\title{
Development and Clinical Application of Liquidchip Luminex Assay in the Detection of Epidermal Growth Factor Receptor and K-Ras Mutation
}

Yan Zhou ${ }^{1,2^{*}}$, Yangyang $\mathrm{Xu}^{2}$, Xiaoqian Wang ${ }^{2}$, Xiaohui Liang $^{2}$ and Jiatao Lou ${ }^{2^{*}}$

${ }^{1}$ Department of Microbiology and Immunobiology, Harvard Medical School, Boston, MA, USA

${ }^{2}$ Department of Laboratory Medicine, Shanghai Chest Hospital, Shanghai Jiao Tong University, Shanghai, China

*Corresponding author: Yan Zhou, New Research Building, Rm 854, 77 Avenue Louis Pasteur, Boston, MA, 02115, USA, E-mail: Yan_Zhou@hms.harvard.edu Jiatao Lou, Department of Laboratory Medicine, Shanghai Chest Hospital, Shanghai Jiao Tong University, Shanghai, China, E-mail: loujiatao@126.com

Received date: August 05, 2017, Accepted date: August 11, 2017, Published date: August 14, 2017

Copyright: $\odot 2017$ Zhou Y, et al. This is an open-access article distributed under the terms of the Creative Commons Attribution License, which permits unrestricted use, distribution, and reproduction in any medium, provided the original author and source are credited.

\begin{abstract}
Purpose: The success of molecular targeted cancer therapy relies on the accurate detection of the mutated gene. We attempted to develop a rapid, accurate, high sensitive and specific liquidchip luminex method for the detection of EGFR and K-ras mutation, both of which are important biomarkers for the personalized treatment of advanced lung cancer patients.

Materials and methods: Using the liquidchip technology, we developed a luminex system by combining PCRLDR (Polymerase Chain Reaction- Ligase Detection Reaction) with luminex platform for the detection of EGFR and $\mathrm{K}$-ras mutation. To verify the clinical application of this liquidchip luminex system, we compared its detection results with those from the gold standard sequencing method through analysis of 100 patients.

Results: The developed luminex system showed high flux, sensitivity and specificity for EGFR and K-ras gene mutation detection. Compared with sequencing for the EGFR and K-ras gene mutation detection, this luminex system showed no obvious difference in the mutation rates among different ages, histological classification and TNM stages. However, for the exon 21 L585R and exon 19 (including the E746-A750 deletion mutant), the luminex method showed even more effective and specificity and demonstrated obvious difference to sequencing $(p<0.05)$.

Conclusion: Our liquidchip luminex system has a wide prospect of clinical application, especially for the detection of EGFR exon 21 L585R and 19 and can be used for early screening and individual therapy of patients with lung cancer.
\end{abstract}

Keywords: Lung cancer; Chemotherapy; Growth factor; Polymerase chain reaction

\section{Introduction}

Lung cancer is one of the leading causes of mortality and consists of small-cell lung cancer (SCLC) and non-small-cell lung cancer (NSCLC) [1]. The conventional treatment includes combined chemotherapy, radiotherapy and surgery. However, most patients become resistant to these therapies at later time.

Cancer cells depend on the gain-of-function mutation of oncogenes and/or loss-of-function mutation of tumor suppressor genes (oncogene addiction), leading to the current trend of molecular targeted cancer therapy. Epidermal growth factor receptor (EGFR) is a member of ErbB receptor tyrosine kinase family and frequently mutated in NSCLC cancers [2]. NSCLC patients with somatic EGFR mutations (Table 1) in exon 19, exons 20 or exon 21 are sensitive to tyrosine kinase inhibitors (TKIs), including gefinitib and erlotinib [3]. In contrast, patients with K-ras mutation in codons 12 and 13 are resistant to TKIs [4-6]. Therefore, it is critical to accurately determine the mutation status of EGFR and K-ras for the selection of patients who may benefit from TKI therapy [7].

\begin{tabular}{|l|l|l|l|}
\hline Name & Mutation & Exon & Base change \\
\hline
\end{tabular}

\begin{tabular}{|l|l|l|l|}
\hline $18 \mathrm{M}$ & G719C & 18 & 2155G $>\mathrm{T}$ \\
\hline $19 \mathrm{M} 1[1]$ & E746-A750 del [1] & 19 & 2235_2249 del 15 \\
\hline $19 \mathrm{M} 1[2]$ & E746-A750 del [2] & 19 & 2235_2250 del 15 \\
\hline $19 \mathrm{M} 2$ & L747_T751S & 19 & 2240_2251 del 12 \\
\hline $19 \mathrm{M} 3$ & L747_P753S & 19 & 2240_2257 del 18 \\
\hline $20 \mathrm{M}$ & T790M & 20 & 2369C >T \\
\hline $21 \mathrm{M} 1$ & L858R & 21 & 2573T>G \\
\hline $21 \mathrm{M} 2$ & L861Q & 21 & 2582T >A \\
\hline
\end{tabular}

Table 1: 8 EFGR gene mutations.

Recently, direct sequencing, allele-specific PCR, amplificationrefractory mutation sequencing (ARMS), H\&E-staining, and quantitative real time PCR are available for detection of gene mutation $[2,5,8,9]$. Nevertheless, these techniques are relatively expensive, technically difficult, long procedure for routine application in clinic, and also depend on the quality of the samples [10]. Moreover, due to the non-targeted detection, direct DNA sequencing has a limited sensitivity for the detection of tumor cells containing an EGFR exon 21 L858R mutation and 19 against a background of non-mutant cells [1]. 
Citation: Zhou Y, Xu Y, Wang X, Liang X, Lou J (2017) Development and Clinical Application of Liquidchip Luminex Assay in the Detection of Epidermal Growth Factor Receptor and K-Ras Mutation. J Immuno Biol 2: 128. doi:10.4172/2476-1966.1000128

Page 2 of 8

In this study, we developed a liquidchip luminex system by combining PCR-LDR (Polymerase Chain Reaction- Ligase Detection Reaction) with Luminex platform for the detection of EGFR and K-ras mutation. In comparison to the gold-standard sequencing, liquidchip luminex system has similar sensitivity and specificity, but simple operation, time and money saving. Our study suggests a promising clinical application of liquidchip luminex system for detecting gene mutation and helping physician to stratify patients for molecular targeted cancer therapies.

\section{Methods and Materials}

\section{Patients}

One hundred patients hospitalized in Shanghai Chest Hospital from November 2011 to February 2012 were recruited in this study. All patients received surgery or chemotherapy during these days. The diagnoses of all patients were confirmed by radiographic inspection and pathological examination. Patient's demographics and characteristics were summarized in Table 2. The median age was 60 years (range 50-70). The male/female ratio was 51/49. Among the 90 patients who we followed up, 30 patients are smokers (33.3\%), 16 were squamous cell carcinoma (17.8\%), 63 were adenocarcinoma $(70 \%)$, and 11 were other chest tumors (12.2\%). According to the UICC criterion, 24 patients were classified as stage I (26.7\%), 22 patients as stage II $(24.4 \%), 19$ patients as stage III $(21.1 \%)$ and 25 stage IV $(27.8 \%)$.

\begin{tabular}{|c|c|c|c|}
\hline Classification & Description & Number & Rates \\
\hline \multirow{3}{*}{ Age } & $\geq 60$ & 52 & \\
\hline & $<60$ & 48 & \\
\hline & $! x \pm s$ & $60 \pm 10$ & \\
\hline \multirow[t]{2}{*}{ Sex } & male & 51 & \\
\hline & female & 49 & \\
\hline Smoking & Smoker & 30 & \\
\hline history & Nonsmoker & 60 & \\
\hline \multirow{4}{*}{ Clinical stages } & I & 24 & \\
\hline & II & 22 & \\
\hline & III & 19 & \\
\hline & IV & 25 & \\
\hline Histological & Adenocarcinoma & 63 & \\
\hline \multirow{3}{*}{ classification } & Squamous cell & & \\
\hline & carcinoma & 16 & \\
\hline & Other lung cancer & 11 & \\
\hline
\end{tabular}

Table 2: Clinical parameter.

\section{DNA extraction}

Genomic DNA was extracted from formalin-fixed paraffinembedded tissue composed of at least 50\% tumor cells with DNeasy Blood \& Tissue Kit (Qiagen). In brief, $50 \mathrm{mg}$ samples were grinded with liquid nitrogen and digested overnight by protease $\mathrm{K}$ at $50^{\circ} \mathrm{C}$, followed by precipitation with buffer AP and buffer $\mathrm{W} 1$. The precipitate was dehydrated in ethanol, resolved in buffer TE and saved at $-20^{\circ} \mathrm{C}$. The concentration and purity of the extracted DNA were assessed by spectrophotometry.

\section{Construction of the reaction system}

EGFR PCR amplifications were carried out in $20 \mu \mathrm{l}$ reaction mixtures containing $1.2 \mu \mathrm{l} 10 \times$ Buffer $2 \mu \mathrm{l}, \mathrm{Mg}^{2+}(25 \mathrm{mmol} / \mathrm{L})$ (or 0.6 $\mu \mathrm{l}$ for K-ras), $2 \mu \mathrm{l}$ dNTPs $(2.5 \mathrm{mmol} / \mathrm{L}), 1 \mathrm{U}$ HotSarTaq DNA polymerase, $4 \mu \mathrm{l} 5 \times$ Q-solution (or $0.5 \mu \mathrm{l}$ for K-ras), primer premixture 4 pairs with $2 \mu \mathrm{l} 1 \mu \mathrm{mol} / \mathrm{L}$ for each single one (2 pairs for K-ras), $2 \mu \mathrm{l}$ genome DNA template ( $4 \mu \mathrm{l}$ for K-ras) $(5 \sim 10 \mathrm{ng})$. PCR parameters, Denaturation at $95^{\circ} \mathrm{C} 15 \mathrm{~min}, 35$ rounds ( 36 for K-ras) of cycling, $94^{\circ} \mathrm{C} 30 \mathrm{sec}$, and $55^{\circ} \mathrm{C}\left(60\right.$ for K-ras), $30 \mathrm{sec}, 72^{\circ} \mathrm{C} 30 \mathrm{sec}$, followed by a final elongation at $72^{\circ} \mathrm{C}$ for $10 \mathrm{~min}$ ( $5 \mathrm{~min}$ or K-ras). EGFR LDR reaction consisted of two steps, pre-denaturation and ligation cycling. $20 \mu \mathrm{LDR}$ reaction mixtures were added into $20 \mu \mathrm{l}$ PCR products. A $20 \mu \mathrm{l}$ reaction system was composed of $2 \mu \mathrm{l} 10 \times$ Ligase Buffer, ligation probe pre-mixture 8 pairs, $4 \mu 11 \mu \mathrm{mol} / \mathrm{L}$ for each single one ( 2 pairs for K-ras), $16 \mathrm{U}$ Taq Ligase. The reaction system was pre-heated at $95^{\circ} \mathrm{C}$ for $5 \mathrm{~min}$, then cycled for 20 rounds at $94^{\circ} \mathrm{C}\left(95^{\circ} \mathrm{C}\right.$ for $\mathrm{K}$-ras) and $55^{\circ} \mathrm{C}\left(62^{\circ} \mathrm{C}\right.$ for $\mathrm{K}$-ras $)$ for $30 \mathrm{sec}$ consecutively.

\section{Luminex array}

Luminex microsphere hybridization system was composed of $22 \mu \mathrm{l}$ microsphere hybridization premixure where microspheres were wrapped up with anti-TAG sequences and $3 \mu \mathrm{L}$ LDR reaction products containing complementary TAG sequences (Luminex). The hybridization mixture was incubated at $45^{\circ} \mathrm{C}$ for $10 \mathrm{~min}$ on PCR instrument. A second incubation was performed in $75 \mu \mathrm{l}$ SA-PE. Signal intensity was detected by Luminex 200.

\section{PCR primers design}

4 pairs of EGFR amplification primers were designed for 18, 19, 20, 21 exons in EGFR gene (NM_005228) using Primer Express 3 online design software (Table 3). K-ras primers were designed for exon 2 in K-ras gene (NM_033360.2) using the same software (Table 3). PCR primers were synthesized by Shanghai Biological Engineering Company. 8 EGFR or K-ras mutation sites in PCR products were detected by LDR. Upstream probe had a 24 bp TAG sequence in 5' end and a 22-27 bp specific sequence in 3' end, whereas downstream probe held a 20-24 bp specific sequence (Table 2). The 5' and 3' end of the downstream probes were phosphorylated and biotinated, respectively. 
Citation: Zhou Y, Xu Y, Wang X, Liang X, Lou J (2017) Development and Clinical Application of Liquidchip Luminex Assay in the Detection of Epidermal Growth Factor Receptor and K-Ras Mutation. J Immuno Biol 2: 128. doi:10.4172/2476-1966.1000128

Page 3 of 8

\begin{tabular}{|c|c|}
\hline EGFR 18 reverse primer & C \\
\hline EGFR 19 forward primer & ACAGCTTGCAAGGACTCT \\
\hline EGFR 19 reverse primer & GG \\
\hline EGFR 20 forward primer & CCCCAGCAATATCAGCCTT \\
\hline EGFR 20 reverse primer & A \\
\hline EGFR 21 forward primer & AGTGCTGGGTAGATGCCA \\
\hline EGFR 21 reverse primer & GT \\
\hline K-ras forward primer & СТСТСССАСТGСАTCTGTC \\
\hline K-ras reverse primer & A \\
\hline EGFR L18U ligation probe & CATATCCCCATGGCAAAC \\
\hline EGFR L18L ligation probe & TC \\
\hline EGFR L191(1)U ligation probe & CCTCACAGCAGGGTCTTCT \\
\hline EGFR L191(1)L ligation probe & C \\
\hline EGFR L191(2)U ligation probe & ATCCTGCAGGGAGAGACT \\
\hline EGFR L191(2)L ligation probe & GA \\
\hline EGFR L192U ligation probe & 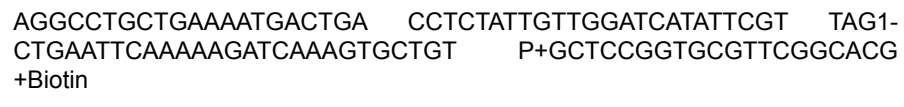 \\
\hline EGFR L192L ligation probe & TAG2-AAAGTTAAAATTCCCGTCGCTATCAA \\
\hline EGFR L193U ligation probe & P+AACATCTCCGAAAGCCAACAAGGA +Biotin \\
\hline EGFR L193L ligation probe & TAG3+AGTTAAAATTCCCGTCGCTATCAA \\
\hline EGFR L790U ligation probe & GP+ACATCTCCGAAAGCCAACAAGGAA + Biotin \\
\hline \multicolumn{2}{|l|}{ EGFR L790L ligation probe } \\
\hline EGFR L211U ligation probe & T P+CATCTCCGAAAGCCAACAAGGAAA + Biotin \\
\hline \multicolumn{2}{|l|}{ EGFR L211L ligation probe } \\
\hline EGFR L212U ligation probe & T P+CGAAAGCCAACAAGGAAATCCTCG +Biotin \\
\hline EGFR L212L ligation probe & TAG6+GCAGCTCATGCCCTTCGGCTG \\
\hline K1M (Gly12Asp) ligation probe & P+ACCTCCACCGTGCAGCTCATCAT+Biotin \\
\hline K2M (Gly12Val) ligation probe & TAG7+TGTCAAGATCACAGATTTTGGGCG \\
\hline K3M (Gly12Ser) ligation probe & P+GGCCAAACTGCTGGGTGCGGA+Biotin \\
\hline K4M (Gly12Cys) ligation probe & TAG8+CACAGATTTTGGGCTGGCCAAACA \\
\hline K5M (Gly12Ala) ligation probe & P+GCTGGGTGCGGAAGAGAAAGAAT+Biotin \\
\hline K6M (Gly12Arg) ligation probe & $\begin{array}{l}\text { TAG1-ATAAACTTGTGGTAGTTGGAGCTGA } \\
\text { TGGCGTAGGCAAGAGTGCCTTG +Biotin }\end{array}$ \\
\hline K7M (Gly13Asp) ligation probe & TAG5+TAAACTTGTGGTAGTTGGAGCTG \\
\hline K8M (Gly13Cys) ligation probe & C P+ TGGCGTAGGCAAGAGTGCCTTG +Biotin \\
\hline $\begin{array}{l}\text { TAG2-ATAAACTTGTGGTAGTTGGAGCTGT } \\
\text { TGGCGTAGGCAAGAGTGCCTTG +Biotin }\end{array}$ & $\begin{array}{l}\text { TAG6+ATATAAACTTGTGGTAGTTGGAGCTC } \\
\text { GTGGCGTAGGCAAGAGTGCCTT +Biotin }\end{array}$ \\
\hline
\end{tabular}




\section{TAG3+ATATAAACTTGTGGTAGTTGGAGCTA} GTGGCGTAGGCAAGAGTGCCTT +Biotin

TAG4+ATATAAACTTGTGGTAGTTGGAGCTT GTGGCGTAGGCAAGAGTGCCTT +Biotin

\begin{tabular}{c|lr|}
$\mathrm{P}+$ & $\begin{array}{l}\text { TAG7+CTTGTGGTAGTTGGAGCTGGTGA } \\
\text { CGTAGGCAAGAGTGCCTTGACG +Biotin }\end{array}$ & $\mathrm{P}+$ \\
$\mathrm{P}+$ & $\begin{array}{l}\text { TAG8+ACTTGTGGTAGTTGGAGCTGGTTG } \\
\text { CGTAGGCAAGAGTGCCTTGACG +Biotin }\end{array}$ & $\mathrm{P}+$ \\
\hline
\end{tabular}

Table 3: Sequence of primers.

\section{DNA sequencing}

Each hot-spot mutation site was amplified by single PCR, followed by DNA sequencing to determine the consistency between PCR-LDRLuminex system and DNA sequencing in detecting EGFR and K-ras gene mutations. DNAs were isolated from the gels, purified and sequenced directly by an ABI-Prism 377 sequencer. All 100 patients were sequenced and detected for the mutation of EGFR and K-ras by the PCR-LDR-Luminex system.

\section{Methodological evaluation}

Cut-off signal intensity: it was defined positive when the hybridization signal was over 200 ascertained with mean fluorescence intensity (MFI), and meanwhile its ratio versus wild type DNA negative control signal was bigger than 1 . The repeatability assessment: we detected the 8 kinds of EGFR and K-ras mutant types mixed with the negative wild type DNA (10000:10000 gene copies) for 10 times, and recorded the mean fluorescence intensity signal to get the mean $\mathrm{CV}$ value. The consistency of the two detection methods was calculated by the mutant number from luminex multiplied by that from sequencing.

Sensitivity: to evaluate the sensitivity of the established assay, using the luminex system, we detected the EGFR gene mutant rates from the EGFR mutants control and the wild type mix (the mutant: wild type $=2000: 10000$ copies). To show the sensitivity of our luminex system comparing to the sequencing, we used the mutant numbers which can be detected by luminex multiplied with the exact numbers from the sequencing.

Specificity: to access the specificity of the established assay, we separately detected the positive mutant control mixed with the wild type DNA=10000:10000 (copies) and the negative control for 3 times simultaneously. To show the specificity of our luminex system among the 100 patients, comparing to the sequencing, we use the negative numbers which detected by luminex times the mutant from the sequencing methods.

\section{Statistical analysis}

The GraphPad prism 5.0 software was used for statistical analysis. The significance $P$ values were analyzed using One-tailed, Fisher's exact test with $95 \%$ confidence interval.

\section{Results}

\section{The performance assessment of liquidchip Luminex assay for the detection of EGFR and K-ras mutation}

Using our luminex assay, we found that EGFR gene rate was between $10 \%-20 \%$, where we only found $1 \%$ with DNA sequencing (Table 1), demonstrating that luminex assay is more sensitive than direct DNA sequencing. The specificity of the luminex system was confirmed by the perfect matching when detecting the positive mutant control, wild type and the negative control (Table 2). Repeatability assay demonstrated the mean CV was $4 \% \sim 15 \%$ (Table 3 ).

\section{EGFR mutation status analysis using sequencing and luminex assay}

We screened EGFR mutation in 100 samples by luminex assay and sequencing. For the luminex assay, there were 39 mutants in the 97 patients (40.2\%) (3 patients failed due to the week signals). With sequencing, 51 mutants were found in the 100 patients (51\%). Thus there was no significant difference between these methods in detecting the mutant rate of EGFR ( $>>0.05)$.

Among the EGFR mutants detected by luminex, $84.6 \%$ resulted from exon 19: E746-A750 deletion (30.7\%) and exon 21: L858R point mutation (53.8\%). While by sequencing, $72.5 \%$ of the EGFR mutations were due to E746-A750 deletion (47.1\%) and exon 21: L858R point mutation (25.5\%). These results indicated that luminex showed an advantage in detecting the hot mutant sites, including the exon 19 and 21 excluded the mixed mutant patients $(\mathrm{p}<0.05)$.

For exon 19 deletion, 17 patients were detected by luminex (43.6\%) in comparison to $24(47.1 \%)$ by sequencing. However, in the 24 patients detected by sequencing, 14 were also found by luminex. Thus, the two methods showed obvious difference $(\mathrm{p}<0.05)$ in detecting exon 19:E746-A750del, 19: delL747-P753insS, 19: delL747-T751. However, apart from the 19 delL747-P753 and delL747-T751, DNA sequencing also detected these rare deletions, including one exon 19 L747-E749del, one 19 L747-S752del, one 20 insertion mutation and one 21 V845L mutation, indicating that luminex can easily detect the most common 15-bp deletion in exon 19 of EGFR and some but not all rare exon 19 deletions.

As to the exon 21 mutations, 22 and 26 patients were detected by luminex and sequencing, respectively ( 2 exon 21 L858R mutant patients failed in the luminex assay). The mutation rate was $56.4 \%$ by luminex, which is higher than by sequencing (49\%). Of the 22 patients detected by luminex, 21 were the L858R (95.5\%). 19 out of 26 patients (73\%) detected by sequencing were excluded from the 3 mixed mutant, 2 failed patients and 2 other sites mutant. The two methods showed obvious difference in the exon 21 L858R detection $(\mathrm{p}<0.05)$. However, they both detected exon 21 L861Q (Table 4).

\begin{tabular}{|l|l|l|l|l|l|}
\hline Methods & $\begin{array}{l}\text { Luminex } \\
\mathbf{( 9 7 )}\end{array}$ & $\begin{array}{l}\text { Sequencing } \\
\mathbf{( 1 0 0 )}\end{array}$ & $\begin{array}{l}\text { Luminex } \\
\mathbf{( 9 7 )}\end{array}$ & $\begin{array}{l}\text { Sequencing } \\
\mathbf{( 1 0 0 )}\end{array}$ & $\begin{array}{l}\mathbf{P} \\
\text { value }\end{array}$ \\
\hline Mutant Sites & Number & & Rates \% & & \\
\hline $\begin{array}{l}\text { Total mutant } \\
\text { number }\end{array}$ & 39 & 51 & 40.2 & 51 & 0.15 \\
\hline 21L858R & 21 & 24 & 21.65 & 24 & 0.73 \\
\hline $\begin{array}{l}\text { 19: E746- } \\
\text { A750del }\end{array}$ & 12 & 13 & 12.37 & 13 & 1 \\
\hline
\end{tabular}


Citation: Zhou Y, Xu Y, Wang X, Liang X, Lou J (2017) Development and Clinical Application of Liquidchip Luminex Assay in the Detection of Epidermal Growth Factor Receptor and K-Ras Mutation. J Immuno Biol 2: 128. doi:10.4172/2476-1966.1000128

Page 5 of 8

\begin{tabular}{|l|l|l|l|l|l|}
\hline $\begin{array}{l}\text { 19:delL747- } \\
\text { P753insS }\end{array}$ & 3 & 1 & 2.06 & 1 & 0.36 \\
\hline $\begin{array}{l}\text { 19: delL747- } \\
\text { T751 }\end{array}$ & 2 & 1 & 3.09 & 1 & 0.61 \\
\hline 21: L861Q & 1 & 1 & 1.03 & 1 & 1 \\
\hline
\end{tabular}

Moreover, the two methods showed no obvious difference in the detecting exon 19 and 21 in different age, sex, smoking, histological classification, and clinical stages. For example, for $\geq 60$ or $<60$ ages people, the two methods demonstrated no obvious difference in the detection of the 21 L858R and 19: delE746-A750. In addition, for the people who smoke or not (female/male, adenocarcinoma/squamous cell carcinoma, type I/II/III/IV clinical stages), similar results were

Table 4: The comparision of Luminex and sequencing in the EGFR found ( $\mathrm{p}>0.05$ ) (Table 5).

mutation detection.

\begin{tabular}{|c|c|c|c|c|c|c|c|c|c|}
\hline & & \multicolumn{4}{|c|}{ 21L858R } & \multicolumn{4}{|c|}{ 19: delE746-A750 } \\
\hline & & \multicolumn{2}{|c|}{ Luminex } & \multicolumn{2}{|c|}{ Sequencing } & \multicolumn{2}{|c|}{ Luminex } & \multicolumn{2}{|c|}{ Sequencing } \\
\hline & & \multicolumn{2}{|c|}{$21(53.85 \%)$} & \multicolumn{2}{|c|}{$24(47.06 \%)$} & \multicolumn{2}{|c|}{$12(30.77 \%)$} & \multicolumn{2}{|c|}{$13(25.49 \%)$} \\
\hline \multirow[t]{3}{*}{ Age } & $\geq 60$ & 13 & 25.00 & 16 & 30.77 & 5 & 9.62 & 4 & 7.69 \\
\hline & $<60$ & 8 & 16.67 & 8 & 16.70 & 7 & 14.58 & 9 & 18.75 \\
\hline & $P$ value & 0.76 & & & & 0.69 & & & \\
\hline \multirow[t]{3}{*}{ Sex } & male & 4 & 7.84 & 7 & 13.73 & 5 & 9.8 & 4 & 7.84 \\
\hline & female & 17 & 34.69 & 17 & 34.69 & 7 & 14.29 & 9 & 18.37 \\
\hline & $P$ value & 0.5 & & & & 0.69 & & & \\
\hline \multirow[t]{3}{*}{ Smoking } & Yes & 2 & 6.67 & 4 & 13.33 & 3 & 10.00 & 3 & 10.00 \\
\hline & No & 16 & 26.67 & 16 & 26.67 & 8 & 13.33 & 9 & 15.00 \\
\hline & $P$ value & 0.66 & & & & 1 & & & \\
\hline \multirow[t]{4}{*}{ Histological classification } & $A D$ & 15 & 23.81 & 15 & 23.81 & 0 & 0.00 & 0 & 0.00 \\
\hline & ScC & 2 & 12.5 & 3 & 18.75 & 11 & 68.75 & 12 & 75.00 \\
\hline & OLC & 2 & 18.18 & 2 & 18.18 & 0 & 0.00 & 0 & 0.00 \\
\hline & $P$ value & 0.91 & & & & & & & \\
\hline \multirow[t]{5}{*}{ Clinical stages } & 1 & 5 & 20.83 & 4 & 16.67 & 4 & 16.66 & 4 & 16.66 \\
\hline & II & 4 & 18.18 & 4 & 18.18 & 2 & 9.09 & 3 & 13.64 \\
\hline & III & 3 & 16.67 & 3 & 16.67 & 1 & 5.26 & 0 & 0.00 \\
\hline & IV & 6 & 24.00 & 9 & 36.00 & 4 & 16.00 & 5 & 20.00 \\
\hline & $P$ value & 0.89 & & & & & & & \\
\hline
\end{tabular}

Table 5: Exon 19 and 21 mutation status comparision of the two methods. AD: adenocarcinoma ; SCC: Squamous cell carcinoma ; OLC: Other lung cancer.

These data demonstrated that the advantage of Luminex system is in the detection of exon 19 E746-A750del and exon 21 L858R for EGFR.

\section{Luminex assay is comparable to sequencing in the detection of K-ras mutation}

We additionally compared luminex assay with sequencing in the detection of K-ras mutation and found both methods detected the $5 \mathrm{~K}$ - ras mutation (3 Gly12Val GGT GTT and 2 Gly12Asp GGTGAT). The 5 K-ras mutation included 4 adenomatous carcinoma (AD) and 1 (SCC) among 1 women and 4 man with 4 Clinical IV stage and 1 Clinical III stage (Table 6). These results demonstrated that luminex assay is comparable to sequencing in the detection of K-ras mutation. 
Citation: Zhou Y, Xu Y, Wang X, Liang X, Lou J (2017) Development and Clinical Application of Liquidchip Luminex Assay in the Detection of Epidermal Growth Factor Receptor and K-Ras Mutation. J Immuno Biol 2: 128. doi:10.4172/2476-1966.1000128

Page 6 of 8

\begin{tabular}{|c|c|c|c|c|c|c|c|c|}
\hline & & \multicolumn{2}{|c|}{ K-ras mutation } & \multirow[t]{2}{*}{$P$ Value } & \multicolumn{2}{|c|}{ Gly12Val (GGTGTT) } & \multicolumn{2}{|c|}{ Gly12Asp (GGTGAT) } \\
\hline & & No & Rates \% & & No & Rates \% & No & Rates \% \\
\hline \multirow[t]{2}{*}{ Age } & $\geq 60$ & 3 & 5.77 & 1 & 3 & 5.77 & & \\
\hline & $<60$ & 2 & 6.25 & & & & 2 & 6.25 \\
\hline \multirow[t]{2}{*}{ Sex } & male & 4 & 7.84 & 0.36 & 2 & 3.92 & 2 & 3.92 \\
\hline & female & 1 & 8.16 & & 1 & 8.16 & & \\
\hline \multirow[t]{2}{*}{ Smoking } & Yes & 3 & 10 & 0.33 & 1 & 1.7 & 2 & 3.3 \\
\hline & No & 2 & 3.3 & & 2 & 3.3 & & \\
\hline \multirow{2}{*}{$\begin{array}{l}\text { Histological } \\
\text { classification }\end{array}$} & $A D$ & 4 & 6.35 & 1 & 3 & 4.76 & 1 & 1.59 \\
\hline & SCC & 1 & 6.25 & & & & 1 & 6.25 \\
\hline \multirow[t]{2}{*}{ Clinical stages } & $\mathrm{Ill \textrm {b }}$ & 1 & 5.56 & 0.38 & 1 & 5.56 & & \\
\hline & IV & 4 & 16.00 & & 2 & 8 & 2 & 8 \\
\hline \multirow[t]{2}{*}{ EGFR mutant } & Yes & 0 & & & 0 & & 0 & \\
\hline & No & 5 & & & 3 & & 2 & \\
\hline
\end{tabular}

Table 6: Distribution of K-ras mutation status. AD: adenocarcinoma ; SCC: Squamous cell carcinoma ; No. Number.

\section{A total comparison of the two Luminex and sequencing methods}

The Luminex-based K-ras mutant detection assays showed 100\% agreement with sequencing. Except for 3 patient samples, which were not tested by the Luminex assay due to the limited DNA amount, 75 (79.4\%) EGFR mutantsdetected by luminex were overlapped with the results with sequencing, which detected 39 mutant and 36 wild types. In addition, set the sequencing as the gold standard, the sensitivity of luminex assay is $97.5 \%$, and the specificity of luminex assay is $89.6 \%$.
These data demonstrated the sensitivity and specificity of this Luminex-based EGFR and K-ras mutant detection system is comparable to sequencing. Comparison of other factors between the two methods was summarized in the Table 7. The major differences are times-cost, money-cost and person requirement. For example, the luminex needs $20 \mathrm{ng}$ DNA, while sequencing requires $50 \mu \mathrm{g}$ DNA. These findings suggest a feasible application of luminex assay for detection of gene mutants in the clinic.

\begin{tabular}{|l|l|l|}
\hline & luminex & Sequencing \\
\hline Person requirement & Short-time train & Long-time train \\
\hline DNA solution requirement & $20 \mathrm{ng}$ & $50 \mathrm{ug}$ \\
\hline Detection sample number & 96 & One by one \\
\hline Operation & Easy & Complex \\
\hline Time-cost & $<2 \mathrm{~h}$ for 96 samples & $>2 \mathrm{~h}$ for 1 samples \\
\hline Money-cost & 1000 & 5000 \\
\hline Sensitivity & ordinary & common \\
\hline Specialist & Very well, especially in the two hot mutant sites & Not be special in some mutant sites \\
\hline Result & Digital signal; Relative quantity & Fluorescence signal; Quality \\
\hline Send report time & That very day for all the samples & Next day for one samples \\
\hline
\end{tabular}

Table 7: Total index comparison for the two methods. 
Citation: Zhou Y, Xu Y, Wang X, Liang X, Lou J (2017) Development and Clinical Application of Liquidchip Luminex Assay in the Detection of Epidermal Growth Factor Receptor and K-Ras Mutation. J Immuno Biol 2: 128. doi:10.4172/2476-1966.1000128

Page 7 of 8

\section{Discussion}

EGFR is a member of the ErbB family, which also includes HER2, HER3, and HER4. Activating mutations in the tyrosine kinase domain play an important role in lung oncogenesis, tumor progression, and clinical efficacy of efitinib or erlotinib. Thus accurate detection of EGFR mutations will determine the success of targeted therapy for lung cancer. In the past decade, many efforts have been made to develop a more specific and sensitive methodology for gene mutation detection. While most if not all, the established techniques have problems for routine usage in clinical laboratories.

Many of these limitations may overcome by particle-based flow cytometric assays, which combined PCR-LDR (Polymerase Chain Reaction- Ligase Detection Reaction) with Luminex platform for the simultaneoud detection of 8 kinds of high frequency EGFR and K-ras gene mutations. First, 8 specific segments containing hot-spot mutation sites in EGFR gene, codon 12 and 13 of K-ras gene were amplified, respectively. Multiplex LDR reaction was performed consequently to ligate upstream and downstream probes whose products carried TAG sequence at 5' end of the upstream probe and biotin at the downstream probe. Luminex reaction system contained 9 coding microsphere, all of which were wrapped up respectively with specific anti-TAG sequences in order to capture correspondent EGFR and K-ras mutation PCR-LDR products. Once upstream and downstream probes were ligated, PCR-LDR products hybridized according to the principle of complementary base pairing with antiTAG probes on microspheres followed by the capture of Biotin products. Then StrepAvidin-PE was added to complete a hybridization system, microspere-anti-TAG probe-PCR-LDR product-BiotinStrepAvidin-PE complex. Finally, Luminex 200 was applied to detect correspondent florescent signal. When analyzed by Luminex detecting software, mutation type was determined by microsphere code whereas quantity of mutation was inspected by the florescent signal intensity. Thus, this technology utilizes microspheres as the solid support for a DNA hybridization assay, which is subsequently analyzed on a flow cytometer (Figure 1).

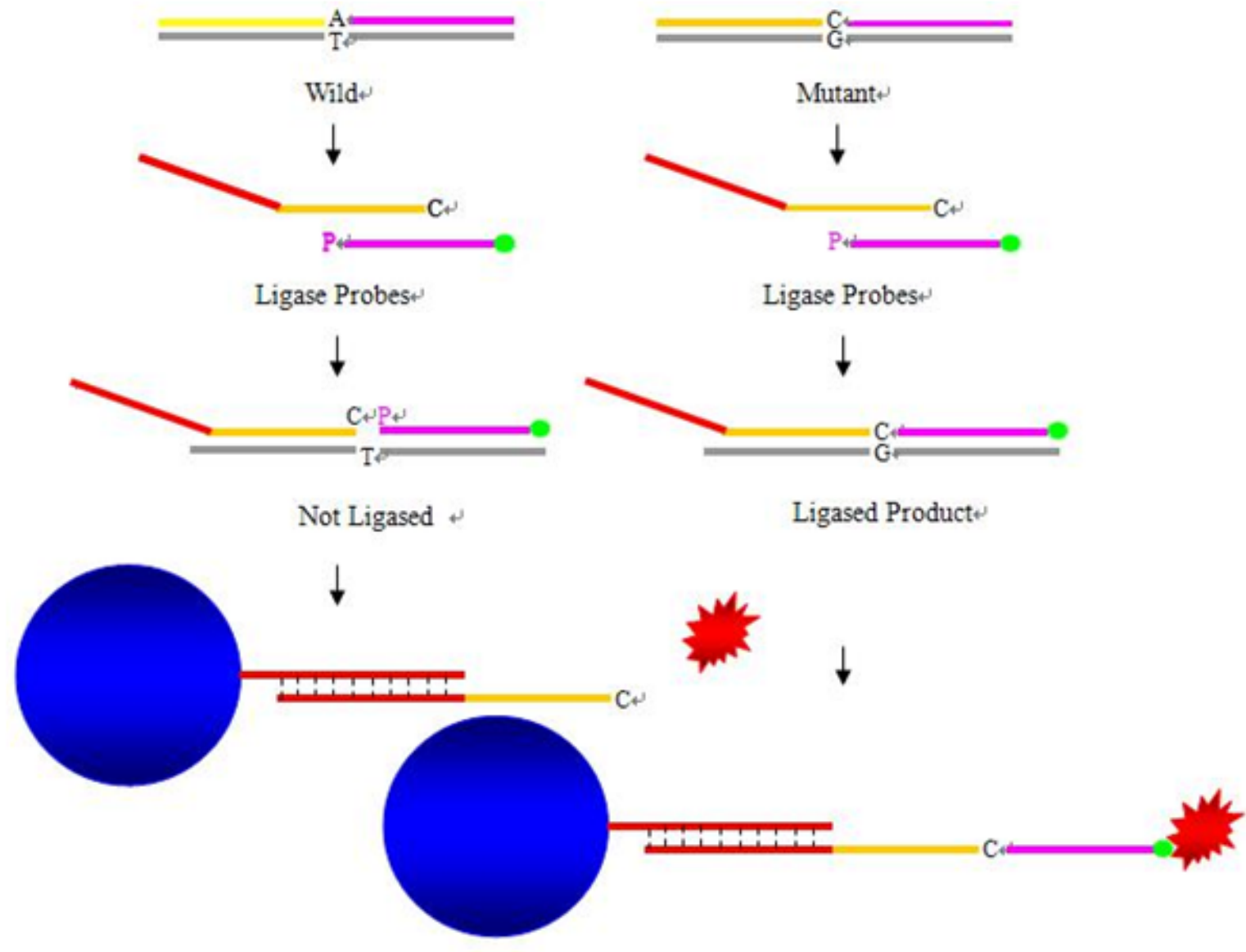

Hybridization

Figure 1: Schematic of detecting EGFR mutations by PCR-LDR reaction combined with liquid chip Note: wild represents EGFR wild DNA PCR products, mutant represents EGFR mutant PCR products. Red segments represent TAG sequence of upper ligating probes. P represents 5' phosphorylation label of lower probes. Green segments represent 3'Biotin label of lower probes. Hybridization represents microspere-probeligating products-fluorescein complex. 
Page 8 of 8

In this study, we developed a multiplexed liquid-chip luminex assay for EGFR and K-ras mutant detection. The results indicate that the assay has potential as a diagnostic tool. To obtain a specific and efficiency reaction condition, we optimized the primer and probe solutions, reaction ratio, annealing temperature, different hybridization temperature and time. Then, the multiple fluorophores were simultaneously detected by the luminex streaming machine from a single PCR reaction tube, and the MFI reading were counted on the computer. In this process, primers and probes for each target may interfere with one another by forming dimers and/or by non-specific partial binding to target sequences, which can be minimized by optimizing primers and probes via appropriate use of sequence conservation and variability among the targets. Our data demonstrated that luminex assay is simple to handle with money- and time saving. Most importantly, it provides for the identification of up to 8 mutant sites in a single reaction, suggesting that mutants can be detected for dozens of patients at the same time.

As direct sequencing of PCR-amplified genomic DNA has been used as the gold standard to detect EGFR and K-ras mutations [11], we compared luminex assay with sequencing and found a high concordance rate $(79.4 \%$ and $100 \%)$ for the detection of EGFR and Kras gene mutation between the two techniques. Further analysis demonstrated that the luminex assay has its advantage over sequencing in the EGFR mutant detection, especially in the EGFR mutant common sites - the 15-bp deletion in exon 19 and the L858R site substitution in exon 21. Our data further showed that The two mutant rates are $17.52 \%$ and $22.68 \%$ individual, compared with the sequencing $15 \%$ and $25 \%(p>0.05)$. For the luminex assay, in the 17 patients with the exon 19 deletion, 12 (70.6\%) had 15-bp deletions (10 with delE746A750-1 and 2 with del E746-A750-2), compared to the sequencing $46.2 \%$ delE746-A750 in all exon 19 deletion; Again, in the 22 patients with exon 21 mutation, 21 (95.5\%) had the same mutation site exon 21 mutation L858R as sequencing $88.9 \%$ (Table 7). Those data demonstrate the luminex method mainly focused on the two sites mutant detection and showed obviously advantages compared with DNA sequencing. As to thethere were $51 \%$ mutant rates of lung cancer patients in our hospital, which is much higher than that in the foreign countries. In addition, the EGFR mutant rates showed obvious difference $(\mathrm{p}<0.05)$ between male and female, smokers and non-smokers as other study reported [12].

But the EGFR mutants were not associated with different tissue types, such as the adenomatous carcinoma and Squamous cell carcinoma. One of the reasons might be that the tumor tissues contained some mixed types. Both methods revealed that the K-ras mutant was $5 \%$, which is similar to the published data from Asia countries [13]. Furthermore, the Luminex technology is flexible. It can be expanded to include more mutant sites, detect the respiratory virus infection, type HPV, and screen for a large panel of intestinal parasites as needed [14,15]. It can also be modified in the future to accommodate more lineage-specific probes for subtyping if necessary. Luminex was demonstrated a more accessible assay than DNA sequencing to rapidly screen EGFR mutations in cancers, especially in the exon 19 and 21 sites. In addition, tumors from other types of cancers have shown some responsiveness to EGFR inhibitors, and high frequency of EGFR mutations (E746_A750del and L858R) has been reported in esophageal, pancreatic, and ovarian cancers. Thus, the detection of EGFR and K-ras mutant status by liquid-chip luminex assay will have a broad perspective for the clinical applications in future.

\section{Acknowledgments}

This work was supported by funding from Ministry of Science and Technology of China (2014DFA33010), Shanghai Hospital Development Center (SHDC22014011).

\section{References}

1. Yu J, Kane S, Wu J, Benedettini E, Li D, et al. (2009) Mutation-specific antibodies for the detection of EGFR mutations in non-small-cell lung cancer. Clin Cancer Res 15: 3023-3028.

2. Wu SG, Chang YL, Lin JW, Wu CT, Chen HY, et al. (2011) Including total EGFR staining in scoring improves EGFR mutations detection by mutation-specific antibodies and EGFR TKIs response prediction. PLoS One 6: e23303.

3. Watanabe S, Tanaka J, Ota T, Kondo R, Tanaka H, et al. (2011) Clinical responses to EGFR-tyrosine kinase inhibitor retreatment in non-small cell lung cancer patients who benefited from prior effective gefitinib therapy: a retrospective analysis. BMC Cancer 11: 1.

4. Do H, Krypuy M, Mitchell PL, Fox SB, Dobrovic A (2008) High resolution melting analysis for rapid and sensitive EGFR and KRAS mutation detection in formalin fixed paraffin embedded biopsies. BMC Cancer 8: 142 .

5. van Eijk R, Licht J, Schrumpf M, Talebian Yazdi M, Ruano D, et al. (2011) Rapid KRAS, EGFR, BRAF and PIK3CA mutation analysis of fine needle aspirates from non-small-cell lung cancer using allele-specific qPCR. PLoS One 6: e17791.

6. Malapelle U, de Rosa N, Rocco D, Bellevicine C, Crispino C, et al. (2011) EGFR and KRAS mutations detection on lung cancer liquid-based cytology: a pilot study. J Clin Pathol 65: 87-91.

7. Sun L, Zhang Q, Luan H, Zhan Z, Wang C, et al. (2011) Comparison of KRAS and EGFR gene status between primary non-small cell lung cancer and local lymph node metastases: implications for clinical practice. J Exp Clin Cancer Res 30: 30.

8. Zhang H, Zheng X, Ji T, Fu L, Bai D, et al. (2011) Comparative Screening of K-ras Mutations in Colorectal Cancer and Lung Cancer Patients Using a Novel Real-Time PCR with ADx-K-ras Kit and Sanger DNA Sequencing. Cell Biochem Biophys 62: 415-420.

9. Santis G, Angell R, Nickless G, Quinn A, Herbert A, et al. (2011) Screening for EGFR and KRAS mutations in endobronchial ultrasound derived transbronchial needle aspirates in non-small cell lung cancer using COLD-PCR. PLoS One 6: e25191.

10. Simonetti S, Molina MA, Queralt C, de Aguirre I, Mayo C, et al. (2010) Detection of EGFR mutations with mutation-specific antibodies in stage IV non-small-cell lung cancer. J Transl Med 8: 135.

11. Liu Y, Liu B, Li XY, Li JJ, Qin HF, et al. (2011) A comparison of ARMS and direct sequencing for EGFR mutation analysis and Tyrosine Kinase Inhibitors treatment prediction in body fluid samples of Non-Small-Cell Lung Cancer patients. J Exp Clin Cancer Res 30: 111.

12. Ren JH, He WS, Yan GL, Jin M, Yang KY, et al. (2012) EGFR mutations in non-small-cell lung cancer among smokers and non-smokers: a metaanalysis. Environ Mol Mutagen 53: 78-82.

13. Zhong W, Chen M, Xian L, Li M (2011) Study on point mutations of Kras gene in non-small cell lung cancer in Guangxi. Zhongguo Fei Ai Za Zhi 14: 507-511.

14. Taniuchi M, Verweij JJ, Noor Z, Sobuz SU, Lieshout Lv, et al. (2011) High throughput multiplex PCR and probe-based detection with Luminex beads for seven intestinal parasites. Am J Trop Med Hyg 84: 332-337.

15. Pabbaraju, Tokaryk KL, Wong S, Fox JD (2011) Comparison of the Luminex XTAG respiratory viral panel with xTAG respiratory viral panel fast for diagnosis of respiratory virus infections. J Clin Microbiol 49: 1738-1744. 